\title{
Significance of apigenin and rosmarinic acid mediated inhibition pathway of MurG, MurE and DNA adenine methylase enzymes with antibacterial potential derived from the methanolic extract of Ocimum sanctum
}

\begin{abstract}
Literature have ample evidence which showed that plant based secondary metabolites have profound antibacterial effect against pathogenic bacteria, but information regarding how the effect was generated is lacking. In the present study, we examined the effect of secondary metabolites from $O$. sanctum both in vitro and in silico to decode the probable pathway of inhibition. Experiments were divided into two parts-Wet and Dry lab experiments. In wet lab experiments, K. pneumoniae was taken as representative bacteria to evaluate the antibacterial potential of secondary metabolites present in different organic extracts of $O$. sanctum using agar-well diffusion and XTT-colorimetric methods. In dry lab experiments, 5 important secondary metabolites viz. Apigenin, Carvacrol, Eugenol, Ocimarin and Rosmarinic acid were docked against 5 essential enzymes of bacteria like Succinate dehydrogenase, MurG, MurE, DNA adenine methylase and DNA primase to assess their antibacterial potential in silico using Auto Dock Vina (1). The enzyme-ligand interaction of docked complexes was further analyzed by Molecular Dynamics Simulation technique using GROMACS(4.6.6). As per wet lab results, methanolic extract was found to be the most promising extract having highest antibacterial potential, where at $20 \mathrm{mg} / \mathrm{ml}$ concentration of the extract there was complete inhibition of bacterial growth. As per dry lab results, Apigenin and Rosmarinic acid were found to be the most successful secondary metabolites which strongly inhibited MurE, MurG and DNA adenine methylase enzymes in silico. As both these metabolites are present in methanolic extract of $O$. sanctum, hence may be responsible for bactericidal effect of $O$. sanctum.
\end{abstract}

Keywords: antibacterial, phytomedicines, docking, molecular simulation
Volume 2 Issue 2 - 2018

\author{
Vikas Pahal, ' Urmila Devi,' Maneet singh,'² \\ Shefali Agnihotri, ${ }^{2}$ Puneet Kaur, ${ }^{2}$ Krishan \\ Swaroop Dadhich ${ }^{3}$ \\ 'Department of Microbiology, Dolphin (PG) college of science \\ and agriculture, India \\ ${ }^{2}$ Department of Bioinformatics, ADI Biosolution, India \\ ${ }^{3}$ Department of Microbiology, Punjab University, India
}

Correspondence: Vikas Pahal, Department of Microbiology, Dolphin (PG) college of science and agriculture, India, Email vikaspahal@gmail.com

Received: April 12, 2018 | Published: April 24, 2018
Abbreviations: OD, optical density; CFU, colony forming unit; DMSO, dimethyl sulphoxide; SD, standard deviation; ZOI, zone of inhibition

\section{Introduction}

Bacterial infections account for the large number of morbidity and mortality cases worldwide, which further have been increased manifold due to evolution of Multiple Drug Resistance (MDR) bacterial strains-resulted from inconsequential use of antibiotics. ${ }^{1}$ To counter this problem scientific community depends upon one of the most reliable alternative remedies i.e. phytomedicines, which are preferred to synthetic drugs on account of their being harmless, effective and economical. ${ }^{2}$ Plants defense system depends on the phytochemicals of secondary metabolites like tannins, alkaloids, flavonoids, phenols, volatile essential oils, terpenes etc. which enable them to fight against predators and pathogenic microorganisms. During evolution of plant defense system, these naturally occurring phytochemicals get evolved with such an unique built-in chirality that helps them to bind or manipulate the functioning of biologically important enzymes and receptors which make them effective bactericidal agents. ${ }^{3}$ Literature on importance of phytochemicals has given testimonials to the success story of many plant derived phytochemicals which were used against various human ailments. ${ }^{4-8}$ But, there is scanty information regarding the mechanism of inhibition of bacterial infections by plant secondary metabolites. Study of the mechanism of inhibition by the secondary metabolites is very important because decoding the pathway of inhibition will help us in understanding the underlying principle of infection, and secondly, it will help the scientist to design new and improved synthetic metabolites that will have profound and desirable inhibitory powers to inhibit the various pathways of bacterial infections. O.sanctum (holy basil) belongs to Lamiaceae family and is one of the wellknown herbs of Indian subcontinent having well documented health benefits such as antibacterial, antiviral, antifungal, anticancerous and antioxidant activities. ${ }^{9}$ It contains various secondary metabolites like eugenol, saponins, flavonoids, flavonols, terpenoids, alkaloids and phenolic compounds. The bioactive phytochemicals such as Apigenin, Eugenol, Ocimarin, Rosmarinic acid, Carvacrol, Urosolic acid, Estragol etc. are present in the leaves of $O$. sanctum. These secondary metabolites are said to be responsible for its medicinal properties. ${ }^{10}$ In the present paper, we tried to decode the probable pathway by which some secondary metabolites from $O$. sanctum inhibit the pathogenesis of bacterial infection by obstructing the action of various important enzymes. Klebsiella pneumoniae, gram-negative pathogenic bacteria, was taken as model bacteria for study. ${ }^{11}$ The project was done in two 
parts: In the first part, known as wet lab experiments, we have isolated the various active constituents of $O$. sanctum using different organic solvents like hexane/ethyl acetate, chloroform, acetone, methanol and water. The bactericidal effects of these various organic extracts were analyzed using two methods: agar-well diffusion method and XTTcolorimetric method. In Second part, known as dry lab experiments, we used various bioinformatics softwares and programme to find out the probable mechanism of inhibition of $K$. pneumoniae by various phytochemicals present in different organic extracts of $O$. sanctum.

\section{Materials and methods}

\section{Wet-lab experiments}

Wet lab experiments were done to reconfirm the antibacterial effect of various organic extracts of $O$. sanctum and the extracts were further analyzed for the presence of various medicinally important phytochemicals.

\section{Chemicals and glass wares}

All the glass wares like test tubes, petri plates, beakers etc. were purchased from borosil, India. All the chemicals used in the present study were of analytical grade. Nutrient agar and broth were purchased from Hi Media Pvt. Ltd, India. Menadione and XTT-salt were purchased from Sigma-Aldrich, India. Organic solvents like hexane, ethyl acetate, chloroform, methanol and acetone were purchased from Merck, India.

\section{Leaves collection and processing}

The leaves of $O$. sanctum were collected, washed with sterile double distilled water and air dried at room temperature $\left(35-40^{\circ} \mathrm{C}\right)$ for 5-7 days. After that, leaves were homogenized to a fine powder using a sterilized mixer grinder and stored in air tight bottles. First of all, hexane and ethyl acetate $(50: 50 \mathrm{v} / \mathrm{v})$ extraction was done for $72 \mathrm{hrs}$ to isolate the essential oils and other fatty acids using Soxhlet assembly. Then, defatted material was used for cold-percolation method to isolate the active principles using various organic solvents. Preparations were filtered through a sterilized filter paper (Whatman No. 1) and was finally concentrated to dryness under vacuum at $40-50^{\circ} \mathrm{C}$ using a rota-evaporator. The dried extracts were then sterilized by UV-irradiation (30-40 minutes with regular shuffling), checked for sterility on nutrient agar plates and stored at $40^{\circ} \mathrm{C}$ in sterile glass bottles until further use.

\section{Test microorganism}

Gram-negative bacteria strain of Klebsiella pneumoniae (MTCC 432) was obtained from Institute of Microbial Technology (IMTECH), Sector 39, Chandigarh, U.T, India. Bacterial culture was freshly cultured before testing by transferring them on to nutrient broth and incubated at $37^{\circ} \mathrm{C}$. The stock cultures were then sub-cultured at regular intervals for further use during antimicrobial activity testing.

\section{Screening for antimicrobial activity}

K. pneumoniae was grown overnight in broth at $37^{\circ} \mathrm{C}$ for $18-20$ hrs. Midlogarithmic phase organisms were harvested by inoculating this culture into $50 \mathrm{ml}$ of fresh broth for additional 2.5 to $3.5 \mathrm{hrs}$ at $37^{\circ} \mathrm{C}$. The bacteria were then centrifuged for $1000 \mathrm{~g}$ for 10 minutes at $40^{\circ} \mathrm{C}$, washed with $10 \mathrm{mM}$ sodium phosphate buffer $(\mathrm{pH}=7.4)$, and resuspended in the same cold buffer. The optical density of an aliquot was measured at $620 \mathrm{~nm}$ and the concentration of bacteria was standardized $\left(\mathrm{OD}_{620} 0.20=5 \mathrm{X} 10^{7} \mathrm{CFU} / \mathrm{ml}\right){ }^{12}$ Antimicrobial studies were carried out using cup (well) assay method also known as agar well diffusion method. Approximately, $20 \mathrm{ml}$ of pre autoclaved agar media cooled at $45^{\circ} \mathrm{C}$ was poured into petri plates and allowed to solidify at room temperature. One hundred micro liter $(100 \mu \mathrm{L})$ of the inoculum of test organism was spread onto the agar plates so as to achieve a confluent growth. Then five wells were made with a sterile borer in the inoculated agar plates. The lower portion of each well was sealed with 2-3 $\mu 1$ molten agar medium. Initially, stock concentration of 40 $\mathrm{mg} / \mathrm{ml}$ was prepared with $8 \%$ DMSO and different concentrations of extracts were made. The concentrations used in agar well diffusion method were $10 \mathrm{mg} / \mathrm{ml}, 5 \mathrm{mg} / \mathrm{ml}, 2.5 \mathrm{mg} / \mathrm{ml}$ and $1.25 \mathrm{mg} / \mathrm{ml}$. A $100 \mu \mathrm{L}$ volume of each extract was propelled directly into the wells of the inoculated agar plates. The plates were allowed to stand for $1-1.5$ hour at room temperature for diffusion of the extract into agar and further incubated at $37^{\circ} \mathrm{C}$ for $18-24$ hours. $8 \%$ DMSO served as the negative control and antibiotic ciprofloxacin served as the positive control. The experiments were performed in triplicate and the mean values of the diameter of Zone of Inhibition (ZOI) were calculated in millimeter scale ( \pm standard deviations). This complete procedure was carried out under aseptic conditions in laminar airflow chamber. ${ }^{13}$

\section{Measurement of antimicrobial activity using XTT-colorimetric method}

Antimicrobial activity with different concentrations of plant extract was also evaluated by the XTT-colorimetric method.14 The XTT assay is an indirect method which measures the microbial activity by assessing the Electron Transport System (ETS) activity using redox dyes (artificial electron acceptors) that can successfully compete with oxygen for electrons. The tetrazolium salt XTT $(2,3-$ bis [2-methyloxy-4-nitro-5-sulfophenyl]-2H-tetrazolium-5carboxanilide) is reduced by the dehydrogenase enzymes of ETS system to a water soluble formazan dye, the absorbance of which can be measured colorimetrically at $490 \mathrm{~nm}$. The measurement of relative reduction in formazan overall provides an estimation of antimicrobial activity. Briefly, Overnight broth culture of bacteria was diluted with nutrient broth to achieve the standard concentration of bacteria $(5 \mathrm{X} 107 \mathrm{CFU} / \mathrm{ml})$ and $170 \mu \mathrm{l}$ of the adjusted broth cultures were added to $96-$ well flat-bottom plate. $30 \mu 1$ of different concentration of plants extract were added to the well with gentle mixing, and incubated for 15 hours. On second day, $100 \mu 1$ of each well material was transferred into new 96-well flat-bottom plate. Fresh solution of XTT+ menadiaone was made and $25 \mu 1$ of that solution was added to each well with gentle mixing. Plates were incubated for 1 hour at $37^{\circ} \mathrm{C}$ and the reading was taken at $490 \mathrm{~nm}$ with the help of Platereader. Negative control was the media containing bacteria without any growth inhibitor and positive control was the media with bacteria and antibiotic ciprofloxacin $(1 \mathrm{mg} / \mathrm{ml})$. Final readings were adjusted after deducting the reading of various blanks. These blanks were: individual reading of pure media, media $+\mathrm{XTT} /$ menadione solution, and media + XTT/menadione solution + antibiotic or different extracts having different concentrations. Experiment was performed in triplicate and final reading was taken as mean $(+\mathrm{SD})$. Antimicrobial activity was measured as percentage reduction of bacterial growth

Percentage reduction $(\% \mathrm{Rd})=\frac{100 \%-[\text { Experiment well absorbance at } 490 \mathrm{~nm} \text { - Blank absorbance }) \times 100]}{\text { Negative control absorbance at } 490 \mathrm{~nm}}$

Negative control absorbance at $490 \mathrm{~nm}$ 


\section{Test for phytochemicals}

Standard protocols were used to find out the presence of different phytochemicals in different organic extracts of $O$. Sanctum..$^{14,15}$

\section{Test for alkaloids}

Two tests were performed to find out the presence of alkaloids in various samples.

In Mayer's test, extracts were treated with the Mayer's reagent (Potassium Mercuric Iodide). A yellow coloured precipitate indicates the presence of alkaloids. In Dragendroff's test, extracts were treated with solution of Potassium Bismuth Iodide (called Dragendroff's solution). Red coloured precipitate revealed the presence of alkaloids.

\section{Test for phenols}

First test: In this test, which is called Gelatin test, $1 \mathrm{ml}$ of $1 \%$ gelatin solution (having $10 \% \mathrm{NaCl}$ ) was added to extracts. If precipitate forms then it indicates the presence of Phenolic compounds.

Second test: Extracts were dissolved in $5 \mathrm{ml}$ water. Then few drops of neutral ferric chloride solution were added drop wise. Presence of dark green colour indicates the phenolic compounds in the extracts.

Third test: Extracts were treated with aqueous ammonia. In presence of air, green colour indicates the presence of phenolic compounds.

\section{Test for saponins}

It is also called foam test. Extracts were shaken with $2 \mathrm{ml}$ of water. Production of foam (at least for 10 minutes) indicates the presence of saponins.

\section{Test for flavonoids}

Various extracts were mixed with $2 \mathrm{ml}$ of methanol (50\%) solution. After warming the solution a small piece of magnesium was added, followed by dropwise addition of concentrated HCL. Occurrence of orange colour indicates presence of flavones, red colour indicates flavonols and crimson to magenta colour shows presence of flavonones.

\section{Test for tannins}

To the extracts add $1.5 \mathrm{ml}$ water followed by $1.5 \mathrm{ml}$ of $1 \mathrm{M}$ Ferric chloride and observed for blue-black coloration for different types of tannins.

\section{Test for terpenoids}

This test is called Salkowski test. Extracts were mixed with $5 \mathrm{ml}$ of chloroform and filtered. To this filtrate concentrated sulphuric acid was added drop wise. A golden yellow colour revealed the presence of terpenoids.

\section{Test for coumarin}

$10 \% \mathrm{NaOH}$ was added to various extracts followed by addition of few drops of chloroform. Observation of yellow colour indicates the presence of Coumarin.

\section{Dry-lab experiments}

In dry lab experiments, 5 potential phytochemicals were tested against 5 important bacterial enzymes using various bioinformatics softwares and programs as shown in Table 1. These phytochemicals are present in different organic extracts of $O$. sanctum.

Table I List of the compounds and protein targets selected for docking studies

\begin{tabular}{ll}
\hline $\begin{array}{l}\text { Name of the } \\
\text { compound }\end{array}$ & Name of the targets \\
\hline Apigenin & Succinate dehydrogenase \\
Carvacrol & MurG \\
Eugenol & MurE \\
Ocimarin & DNA Adenine Methylase \\
Rosmarinic acid & DNA Primase \\
\hline
\end{tabular}

\section{Retrieval of protein sequences and homology search}

The retrieval of protein sequences for five target proteins/ enzymes (MurG, MurE, DNA adenine methylase, DNA primase and Succinate dehydrogenase) of $K$. pneumoniae were retrieved from National Center for Biotechnology Information. Blast was done to find similarity search for five target proteins. After analyzing similarity, protein modelling for all the five protein targets was done using Modeler 9.15. Then, on the basis of lowest DOPE (discrete optimized protein energy) score, best model was selected for all the five targets. After that, the quality of the target model was analyzed using Ramachandran plot and Prosa web server. From the analysis, it was concluded that all the protein residues were found to be present in the allowed region of the Ramachandran plot and the proteins were considered as of good quality target proteins. ${ }^{16}$

\section{Selection and properties of compounds}

Five compounds of $O$. sanctum viz. Apigenin, Ocimarin, Eugenol, Rosmarinic acid and Carvacrol were selected for drug docking studies. Structures of these ligand molecules were retrieved from Pubchem server. The compounds were screened by the "Lipinski's rule of five" in the ISIS BASE and were found to display significant drug-like properties such as molecular weight $\leq 500, \log \mathrm{P} \leq 5$, number of $\mathrm{H}$-bond donors $\leq 5$, number of $\mathrm{H}$-bond acceptors $\leq 10$, etc. The selected bioactive compounds were drawn in Molinspiration to predict bioactivities and molecular properties. The 3D structures of the selected compounds were drawn and the corresponding files (pdb) were downloaded using Chem Sketch programme. All of the structures were viewed using PyMOL. ${ }^{16-19}$ Apigenin (5,7-dihydroxy-2-(4-hydroxyphenyl) chromen-4-one), insoluble in water but soluble in organic solutions, is known as one of the bioflavonoid compounds that is commonly recognized as a bioactive flavonoid (or flavones) and its antioxidant, anti-inflammatory, anti-stress properties and antimicrobial properties have been scientifically proven. ${ }^{20}$ Rosmarinic acid (2R-3- $(3,4-$ dihydroxyphenyl)-2-[(E)-3-(3,4-dihydroxyphenyl) prop-2-enoyl] oxypropanoic acid) belongs to the group of polyphenols and possesses antioxidant, anti-inflammatory and antimicrobial activities. ${ }^{21}$ Carvacrol (2-methyl-5-propan-2-ylphenol) is a monoterpenoid phenol present in the essential oil of various plants. Carvacrol has been observed to possess good inhibitory properties against several bacterial strains, e.g. Escherichia coli and Bacillus cereus. Eugenol (2-methoxy-4-prop-2-enylphenol) is an allyl chain-substituted guaiacol, and is a clear to pale yellow oily liquid found in essential oils. Ocimarin is 7-hydroxy-3-(2-hydroxyethyl)-4-methyl- 
chromen-2-one, a naturally occurring compound which is soluble in various alcohols. ${ }^{22-24}$

\section{Molecular docking analysis}

The process of docking involves the binding of drug molecule to the active site of its receptor molecule. The active sites present in the targets proteins were identified using Ligsite. Ligsite is a programmer which is used for the automatic detection of pockets (binding sites for ligands or drug molecules) on the surface of proteins. The docking was performed using software Auto Dock Vina (1), which is based on Lamarckian genetic algorithm (LGA) to scan protein-ligand interactions and complete the process by assigning a binding energy to each conformation. In the following steps, polar hydrogen was added and the protein molecules were assigned with Kollman united atom charge followed by generation of PDBQT file. Autogrid programme was used to generate $3 \mathrm{D}$ affinity grid fields with grid map of $40^{\circ} \mathrm{A}$ $\times 40^{\circ} \mathrm{A} \times 40^{\circ} \mathrm{A}$ points, which encloses the entire groove near the active site to fit the ligand. The best docking results are always the one having lowest energy. ${ }^{25}$ Amino acids residues within the circumference of $4.0 \AA$ around the molecule in the molecular docking were represented as active sites for binding. The binding free energy between the active site and ligand was calculated using CIE (Calculate Interaction Energy) programme. Only those amino acids were considered as key molecules whose absolute values of interaction energy (Vander Waals forces \& electrostatic energy) with ligands were above $2.5 \mathrm{kcal} / \mathrm{mol}$, and were selected for further study. The structural models of targeted enzymes were constructed by Discovery Studio. Lig Plots of the docked complexes were derived using Lig Plot $^{+}$(V.1.4.5) to derive unambiguous images of the hydrophobic interactions with respect to amino acid residues in the enzyme under the study. ${ }^{26}$

\section{Molecular dynamics simulation and analysis of molecular dynamics trajectory}

To analyze the stability of protein-ligand complex, simulation was done using command-line based software GROMACS (4.6.6) under Ubuntu 14.04 operating system. ${ }^{27}$ The lowest binding energy (most negative) docking conformation generated by Auto Dock was considered as initial conformation for MD simulation. The molecules were placed in the center of a dodecahedron box and subsequently filled with water molecules. Then, the system was neutralized by adding sodium ions $\left(\mathrm{Na}^{+}\right)$in each box. After standard equilibration procedure a MD cycle was run and potential energy of protein was analyzed and stability of the binding was evaluated. The protein and the ligand complex were energy minimized by steepest descent of 5000 steps. In order to equilibrate the system, the system was exposed to position-restrained dynamics simulation: NVT (constant number of atoms $\mathrm{N}$, volume $\mathrm{V}$ and temperature $\mathrm{T}$ ) and NPT (constant number of atoms $\mathrm{N}$, pressure $\mathrm{P}$ and temperature $\mathrm{T}$ ) ensemble at $300 \mathrm{~K}$ for $100 \mathrm{ps}$ to equilibrate the system and finally the whole system was subjected to the MD run at $300 \mathrm{~K}$ temperature and 1 bar pressure for simulation time of 50,000 ps. Modified Berendsen thermostat coupling scheme algorithm was employed for both ensembles of equilibration. All the trajectories were recorded and stored for further analysis. The trajectory files were explored by using GROMACS utilities in order to obtain the root-mean-square deviation (RMSD). Energy fluctuations and RMSD of the complex in each trajectory were analyzed with respect to simulation time. The numbers of hydrogen bonds formed during the simulation were calculated using gh bond utility. Gh bond was used to cross check the docking results in terms of hydrogen bonding pattern between the receptor and the ligand. Gh bond uses a default distance cutoff of $3.5 \mathrm{~A}^{\circ}(0.35 \mathrm{~nm})$ and a default angle cutoff of 30 degrees (i.e. bond angle must be 300 or greater). All the trajectories results were analyzed and graphs were plotted using XMGRACE programme. MD simulation probe molecular motion on the atomic scale as a function of time. Stability, structure formation, flexibility, functions and association of molecules in a biomolecular structure can be studied at high resolution in space and time using this programme. ${ }^{27-29}$

\section{Results and discussion}

Agar-well diffusion assay results showed that the methanolic extract of $O$. sanctum was found to be the most effective against inhibition of K. pneumoniae growth (ZOI: $21.33 \pm 0.28 \mathrm{~mm}$ ), followed by acetone (ZOI: $12.00 \pm 0.00 \mathrm{~mm}$ ) and hexane/methyl acetate extract (ZOI: $8.66 \pm 0.57 \mathrm{~mm}$ ) as shown in Table 2 and Figure 1. Chloroform extract was found to be the least effective against the bacteria (ZOI: $7.66 \pm 0.57 \mathrm{~mm}$ ). Top three results of agar-well assay were reevaluated by using XTT-colorimetric assay. XTT based results supported the agar-well assay results. Here, again methanol extract was found to be the most potent inhibitor of bacterial growth where upto the concentration of $20 \mathrm{mg} / \mathrm{ml}$, there was complete inhibition of bacterial growth as shown in Table 3. At the concentration of $5 \mathrm{mg} / \mathrm{ml}$, the methanolic extract effectively $(0.408 \pm 0.020)$ inhibited the bacterial growth more than $50 \%$ as shown in Table 3. Acetone extract was found to be the second best inhibitor of K. pneumoniae, whereas at 40 $\mathrm{mg} / \mathrm{ml}$, there was complete inhibition followed by $\mathrm{Hx} / \mathrm{EtAc}$ extract. In case of acetone extract, $10 \mathrm{mg} / \mathrm{ml}$ concentration was found to be the concentration having potential of inhibiting more than $50 \%$ of the bacterial growth $(61.79 \%)$. Wet lab experiments confirmed the high antibacterial potential of methanolic extract followed by acetone and $\mathrm{Hx} / \mathrm{EtAc}$ extract. All the organic extracts were then screened for the presence of various phytochemicals. Methanolic extract showed the presence of high concentration of flavonoid (flavone) and polyphenols. Whereas, hexane/ethyl acetate extract showed presence of high concentration of alkaloids, terpenoids and Coumarin. Chloroform extract showed the presence of low concentration of flavonoid, whereas acetone extract showed the presence of phenols and flavonols as shown in Table 4. Acetone extract was found to have moderatelevel presence of phenols and low levels of flavonoids. Saponins were found to be present in both methanolic and acetonic extracts in moderate concentration. Chloroform extract showed the presence of moderate level of terpenoids and low concentration of flavonoids. All the five enzymes are imperative to survival and propagation of bacterial infection. Succinate dehydrogenase (SDH) is a membranebound enzyme of the TCA (tricarboxylic acid) cycle, which catalyzes the aerobic electron-transport pathway to generate energy in terms of ATP via oxidative phosphorylation reactions. ${ }^{30}$ Docking results shows that Rosmarinic acid and Ocimarin were the most successful phytochemicals to inhibit the SDH enzyme with binding energy of -9.4 and $-7.5 \mathrm{kcal} / \mathrm{mol}$, respectively, followed by Apigenin $(-6.1$ $\mathrm{kcal} / \mathrm{mol})$, Carvacrol $(-4.9 \mathrm{kcal} / \mathrm{mol})$ and Eugenol $(-4.7 \mathrm{kcal} / \mathrm{mol})$ as shown in Table 5 and Figure 2. Peptidoglycan is an integral component of the bacterial cell wall. It is responsible for the mechanical rigidity of cell wall which is required to resist higher osmotic potential and hence maintained cell shape. Cytoplasm is the center of biosynthesis of peptidoglycan precursor, where Mur enzymes are present. MurE and MurG enzymes are required for the biosynthesis of peptidoglycan precursor. ${ }^{31-33}$ Docking results showed excellent inhibitory effect of 
apigenin $(-9.3 \mathrm{kcal} / \mathrm{mol})$ and rosmarinic acid $(-6.5 \mathrm{kcal} / \mathrm{mol})$ against MurE enzyme. Similarly, both these phytochemicals were again found to be the most successful phytochemicals against MurG enzyme, where rosmarinic acid and apigenin shows the binding energy of -7.0 $\mathrm{kcal} / \mathrm{mol}$ and $-7.7 \mathrm{kcal} / \mathrm{mol}$, respectively Table 5 and Figure 2 . The process of DNA methylation regulates various virulent genes of bacteria. This methylase enzyme is responsible for the methylation reaction at $\mathrm{C}-5$ or $\mathrm{N}-4$ positions of cytosine and at the $\mathrm{N}-6$ position of adenine. ${ }^{34}$ Methylation at adenine nucleotide can alter the interactions of regulatory proteins with DNA, which directly influence the pathogenesis of bacteria. As per docking results this enzyme was inhibited by Rosmarinic acid and Apigenin with binding energy $-9.0 \mathrm{kcal} / \mathrm{mol}$ and $-8.1 \mathrm{kcal} / \mathrm{mol}$, respectively. DNA primases are class of proteins that synthesize short RNA primers for accurate initiation of DNA replication process. This enzyme is very important for bacterial reproduction and propagation. ${ }^{35}$ As shown in Table 5 and Figure 2, docking results showed that the DNA primase enzyme was inhibited strongly by Rosmarinic acid $(-7.6 \mathrm{kcal} / \mathrm{mol})$ and Apigenin $(-6.6 \mathrm{kcal} / \mathrm{mol})$, followed by Ocimarin $(-5.7 \mathrm{kcal} / \mathrm{mol})$, Eugenol $(-5.3$ $\mathrm{kcal} / \mathrm{mol})$ and Carvacrol $(-5.2 \mathrm{kcal} / \mathrm{mol})$. In docking results it was observed that the two phytochemicals i.e. Rosmarinic acid and Apigenin were found to be the best inhibitors against all the five bacterial enzymes. The PyMOL and Discovery Studio representation of the various protein-ligands after computational docking are shown in Figure 2. Docking results are not the absolute results to confirm the good inhibitory effects of phytochemicals against various enzymes as stability and quality of docked complex is absolutely imperative to be qualified for a good inhibitor molecules. Improvement of the results of docking can be achieved by different ways- one of them is molecular dynamics simulations of protein-ligand complexes. So, stability and quality of all 25 docked complexes (between 5 enzymes and 5 target proteins, as shown in Table 5 were analyzed by Molecular Dynamics Simulation technique, which analyzes the stability factors based on the analysis of RMSD, potential energy and hydrogen energy graphs of the docked complex. More negative the potential energy, more stable will be the protein-ligand complex, and more stable the protein-ligand complex, more effective will be the inhibitory potential of that ligand. As shown and explained in Figure 3.1, it was found that MurG was best inhibited by Apigenin as the docking complex of apigenin with MurG was found to be the most stable among other docking complexes. This analysis is based on the respective potential energy graph, the temperature plot for protein-ligand and pressure plot for protein-ligand as shown in Figure 3.1 where the stable structure complex of apigenin and MurG enzyme was shown in Py MOL window. The active amino acid residue was Gly11 which form proper $\mathrm{H}$-bonding with the ligand molecule. RMSD graph of enzyme and ligand was found to have stable conformation changes after MD run. The potential energy graph of the above mentioned docking structure shows steady convergence of potential energy after energy minimization that relaxes the structure to ensure that the system has no steric clashes or inappropriate geometry. Once we get the reasonable starting structure, we need to equilibrate the solvent and ions around the protein-ligand under an NVT/NPT ensemble. As per NVT ensemble plot, it was clear that the temperature of the system quickly reaches the target value $(300 \mathrm{~K})$ and remains stable over the remainder of the equilibration. Similarly, NPT plot shows the normal oscillation behavior of the pressure about the desired average (1.05bar). Similarly, the H-bond graph shows the number \& stability of hydrogen bonds was consistent between various ligands and the enzymes after MD run. Rosmarinic acid was found to be the best inhibitors of MurE enzyme and DNA adenine methylase as proved by their respective potential energy graph, the temperature plot for protein-ligand and pressure plot for protein-ligand graph. Binding affinity of rosmarinic acid towards MurE and DNA adenine methylase was found to be highly stable. The active amino acid residue was PRO-181 in case of DNA adenine methylase-rosmarinic acid complex and ARG-326 in case of MurE-rosmarinic acid complex. In both cases, $\mathrm{H}-$ bond graph shows that all the active sites residues have formed stable $\mathrm{H}$-bond and the complex was consistent which form proper bonding with the ligand molecule. Similarly, RMSD graph of enzyme and ligand was found to have stable conformation changes after MD run. RMSD plots revealed that complex was relatively stable throughout the simulation time with slight structural rearrangement $\left(\leq 2 \mathrm{~A}^{\circ}\right)$. Therefore, as per molecular simulation results, it was found that Rosmarinic acid and Apigenin can be considered as competitive inhibitors against enzymes MurE, MurG and DNA adenine methylase. Except these 3 docking complexes all other 22 pairs of protein-ligand complex failed during Molecular Dynamics Simulation, for example, SDH was best inhibited by rosmarinic acid as per the docking results Table 5 and Figure 2, but could not resist the temperature and pressure which resulted in the breaking of the interaction between the SDH enzyme and rosmarinic acid and the drug moved out of the cavity as shown in Figure 3.4.

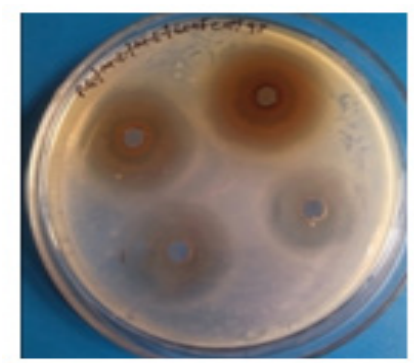

A

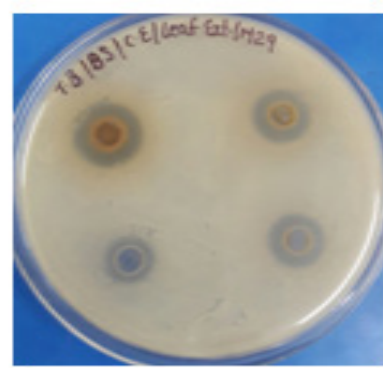

C

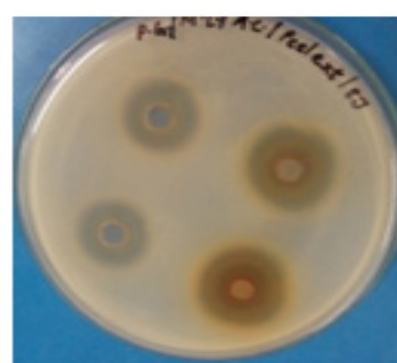

B

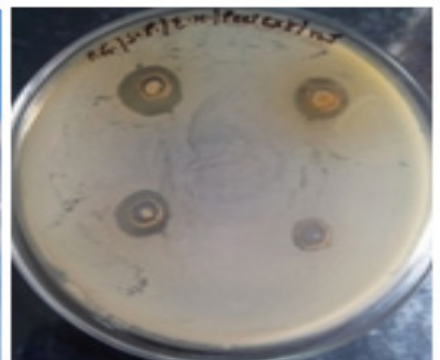

D
Figure I Antibacterial effect of various organic extracts of $O$. sanctum against K. pneumoniae

It is of great importance to investigate the dynamic state of protein-ligand complex by the molecular dynamics simulation technique as all the proteins have dynamic nature in solution and have structural flexibility. The potential energy and root-mean square deviation graphs indicate that ligands have formed stable complex with the protein, whereas the energy plot demonstrates that the energy of the system was relatively consistent during MD simulations run. In MD simulations, solvating water molecules were considered for evaluating durability of the ligand-protein complex in contrast to molecular docking. MD simulations were accredited closer to the 
physiological environmental conditions and it demonstrates better binding conformations for docked complex. So, Apigenin and Rosmarinic acid were found to be the only phytochemicals having proved efficiency as bactericidal agent as per MD simulation results against 3 important enzymes of bacterial origins as explained earlier. Peptidoglycan biosynthesis is an essential step in bacterial replication and propagation. Peptidoglycan is a chemical moiety which is unique to prokaryotic cell. This uniqueness made it excellent choice for targeting by new inhibitor molecules. Different Mur enzymes are involved in biosynthesis of peptidoglycan. For this reason, they are but obvious choice of targeting and synthesis of new potential inhibitors. Rosmarinic acid and Apigenin were shown to inhibit two important Mur enzymes (MurE, MurG), which catalyzes lateral steps of peptidoglycan synthesis. Both of these two phytochemicals were found in methanol extract of $O$. sanctum. ${ }^{34-36}$ As per wet lab experiments, methanolic extract shows best inhibition against $K$. pneumoniae which could due to be the presence of Rosmarinic acid and Apigenin. DNA methylation process is one of the most important levels of regulatory control in bacterial replication. Alteration of methylase levels directly influences the expression of specific genes responsible for accurate propagation of the bacterial pathogenesis. ${ }^{34}$ Rosmarinic acid was found to be the best inhibitor of DNA adenine methylase enzyme as per in silico results. So, this phytochemical may inhibit the growth by inhibiting two important bacterial enzymesMurE and DNA adenine methylase as per results from Molecular Dynamics simulation. In wet lab experiments, methanolic extract was found to be the most effective extract having profound inhibitory effect on the growth of K. pneumoniae. ${ }^{36}$ As both of these compounds were present in methanolic extract. ${ }^{36-39}$ So we can conclude that the phytochemicals of $O$. sanctum, mainly Apigenin and Rosmarinic acid inhibit the growth of bacteria $K$. pneumoniae by inhibiting the enzymes MurE, MurG and DNA adenine methylase. Inhibition is a multifactorial process and inhibition of bacterial cell wall precursor's enzymes and DNA adenine methylase could be some of the pathways inhibited by Rosmarinic acid and Apigenin to control bacterial replication and pathogenesis. However, further study under in vitro conditions is necessary to validate the potential of these compounds as an effective drug against pathogenic bacteria.

Table 2 Results showing zone of inhibition as observed against $K$. pneumoniae by using various organic extracts of $O$. sanctum

\begin{tabular}{lllll}
\hline \multirow{2}{*}{ Extracts } & \multicolumn{2}{l}{ ZOI $(\mathbf{m m} \pm S . D)$} & & \\
\cline { 2 - 5 } & $\mathbf{1 0} \mathbf{m g} / \mathbf{m l}$ & $\mathbf{5 m g} / \mathbf{m l}$ & $\mathbf{2 . 5} \mathbf{m g} / \mathbf{m l}$ & $\mathbf{1 . 2 5} \mathbf{~} \mathbf{g} / \mathbf{m l}$ \\
\hline Hx/EtAc & $8.66 \pm 0.57$ & $6.0 \pm 0.0$ & $4.0 \pm 0.0$ & $3.0 \pm 0.0$ \\
Chloroform & $7.66 \pm 0.57$ & $5.0 \pm 0.0$ & $2.0 \pm 0.0$ & $\mathrm{NIL}$ \\
Acetone & $12.0 \pm 0.0$ & $10.16 \pm 0.28$ & $7.33 \pm 0.57$ & $6.0 \pm 0.0$ \\
Methanol & $21.33 \pm 0.28$ & $16.0 \pm 0.0$ & $9.33 \pm 0.57$ & $7.0 \pm 0.0$
\end{tabular}

Table 3 Measurement of O.D (mean \pm standard deviation) showing growth of bacteria K. pneumoniae in the presence of different concentration of various organic extracts The well containing antibiotic had O.D $(0.079 \pm 0.017)$, whereas the well having negative control had the O.D ( $903 \pm 0.058)$.

\begin{tabular}{|c|c|c|c|c|c|c|}
\hline \multirow{2}{*}{ Extract } & \multicolumn{6}{|c|}{ O.D (mean $\pm S D)$} \\
\hline & $40 \mathrm{mg} / \mathrm{ml}$ & $20 \mathrm{mg} / \mathrm{ml}$ & $10 \mathrm{mg} / \mathrm{ml}$ & $5 \mathrm{mg} / \mathrm{ml}$ & $2.5 \mathrm{mg} / \mathrm{ml}$ & $1.25 \mathrm{mg} / \mathrm{ml}$ \\
\hline $\mathrm{H} x / \mathrm{EtAc}$ & $0.290 \pm 0.078$ & $0.464 \pm 0.029$ & $0.706 \pm 0.046$ & $0.849 \pm 0.028$ & N.E & N.E \\
\hline P.I (\%) & -67.88 & -48.61 & -21.81 & -5.98 & - & - \\
\hline Acetone & C.I & $0.220 \pm 0.023$ & $0.345 \pm 0.043$ & $0.675 \pm 0.025$ & $0.826 \pm 0.040$ & N.E \\
\hline P.I (\%) & C.I & -75.63 & -61.79 & -25.24 & -8.52 & - \\
\hline Methanol & C.I & C.I & $0.170 \pm 0.033$ & $0.408 \pm 0.020$ & $0.588 \pm 0.018$ & $0.78 I \pm 0.034$ \\
\hline P.I (\%) & C.I & C.I & -81.17 & $-54.8 I$ & -34.88 & $-|3.5|$ \\
\hline
\end{tabular}

Table 4 Phytochemical results of various organic extracts of $O$. Sanctum. The nomenclature high, moderate and low concentration is based on intensity of color or precipitate formation in respective confirmatory test

\begin{tabular}{lllll}
\hline $\begin{array}{l}\text { Extract } \\
\text { Ex/EtAc }\end{array}$ & Chl & Act & Met \\
\hline Phytochemical & & & & \\
Alkaloids & +++ & - & - & + \\
Phenols & + & - & ++ & +++ \\
Saponins & - & - & ++ & ++ \\
Flavonoids & - & + & + & +++ \\
Tannins & - & - & - & + \\
Terpenoids & +++ & ++ & + & - \\
Coumarin & ++ & - & - & - \\
\hline
\end{tabular}

[+++: High conc., ++: Moderate Conc., +: Low conc., - : Absent] 


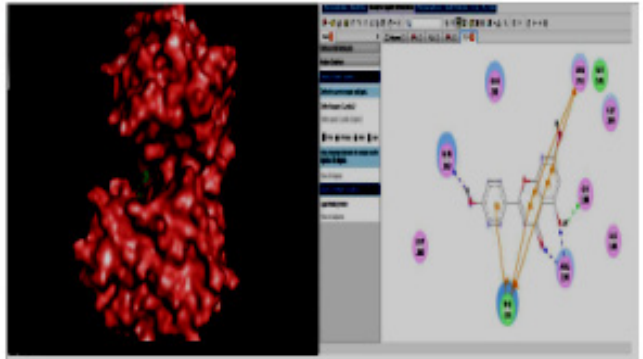

A

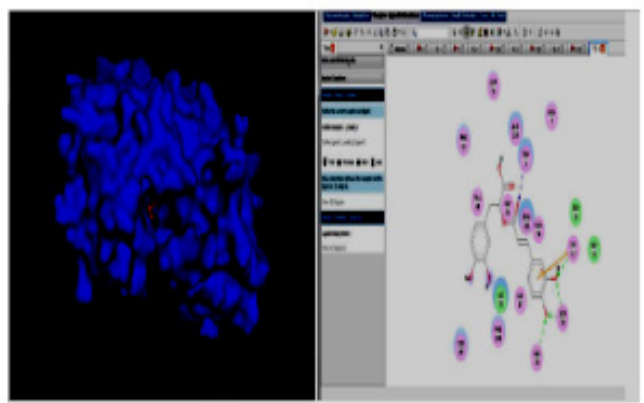

$\mathrm{C}$

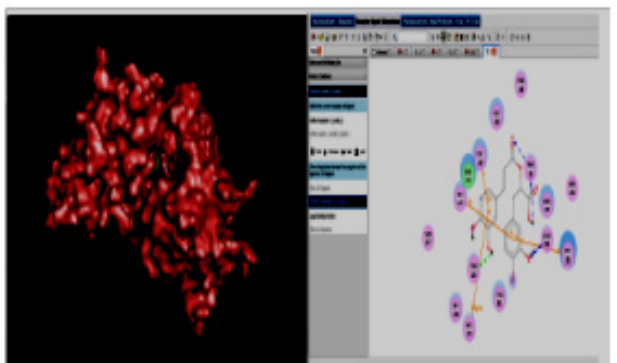

B

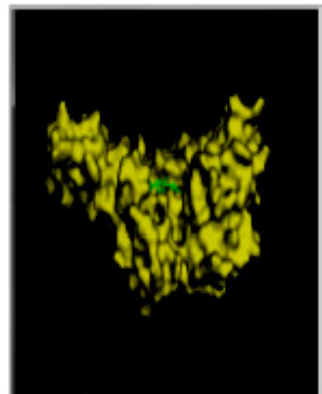

D

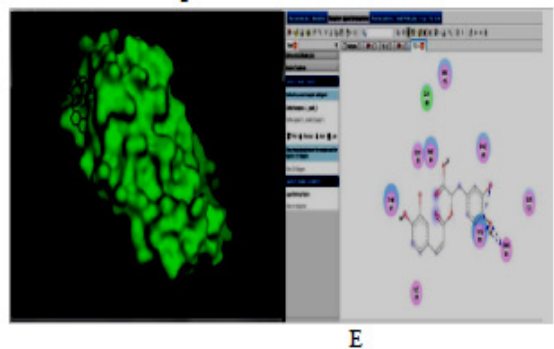

Figure 2 Top docking results of protein-ligand complexes. Each photo is divided into two parts. Left hand side shows the protein-ligand complex in PYMOL, whereas right hand shows the $\mathrm{H}$-bonding pattern of protein-ligand complex in Discovery studio. (A): MurG with Apigenin; (B): MurE with apigenin; (C): DNA adenine Methylase with rosmarinic acid; (D): DNA Primase with rosmarinic acid; (E): Succinate dehydrogenase with rosmarinic acid

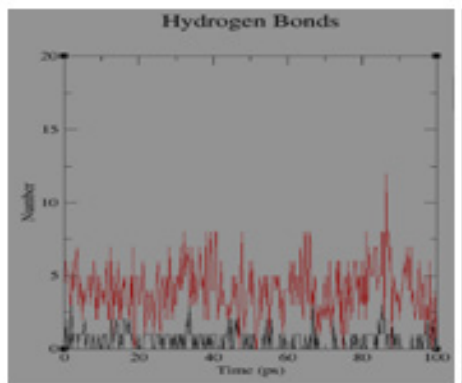

A

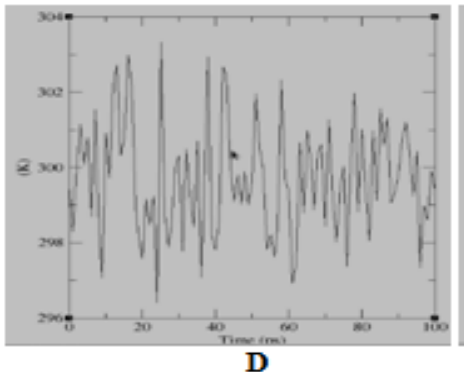

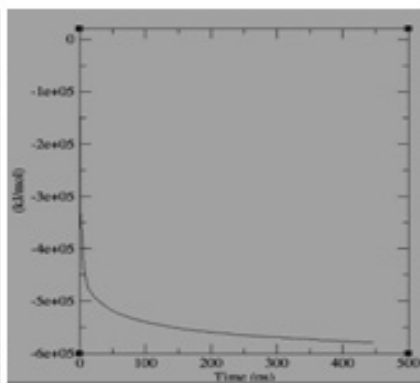

B

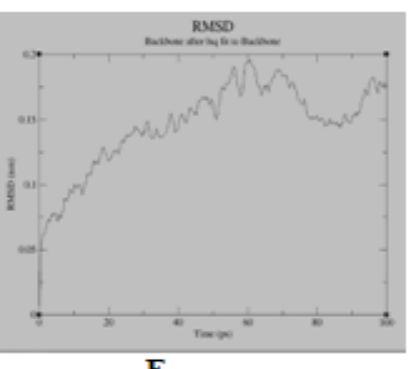

$\mathbf{E}$

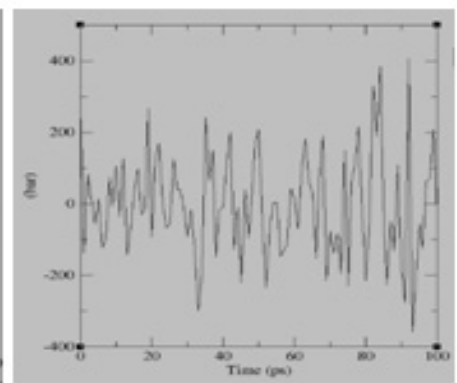

C

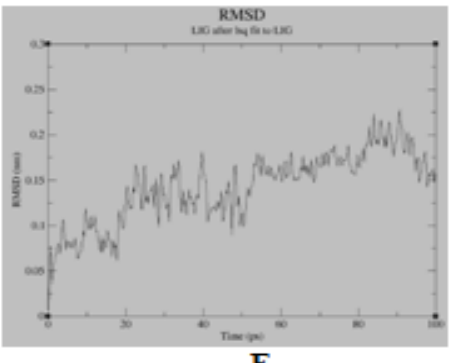

Citation: Pahal V, Devi U, Singh M, et al. Significance of apigenin and rosmarinic acid mediated inhibition pathway of MurG, MurE and DNA adenine methylase enzymes with antibacterial potential derived from the methanolic extract of Ocimum sanctum. MOJ Drug Des Develop Ther. 20I8;2(2):67-77. DOI: I0.I5406/mojddt.20I8.02.0003 | 


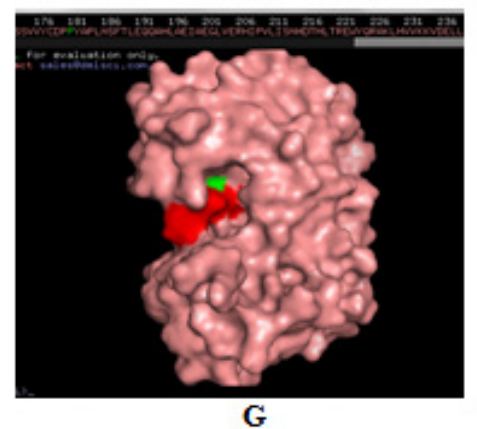

Figure 3.I Molecular simulation results of DNA-adenine methylase \& rosmarinic acid complex. (A) Graph showing hydrogen bonds between the ligand-protein complex within the scale of $0.35 \mathrm{~nm}$; (B) GROMACS energy graph showing potential energy graph between ligand-protein complex; (C) GROMACS energy graph showing pressure graph between ligand-protein complex; (D) GROMACS energy graph showing temperature graph between ligand-protein complex; (E) RMSD graph of protein; (F) RMSD graph of ligand-Drug; (G) Protein (green colour)-ligand (red colour) complex

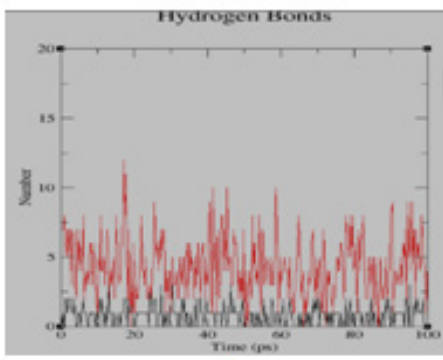

A

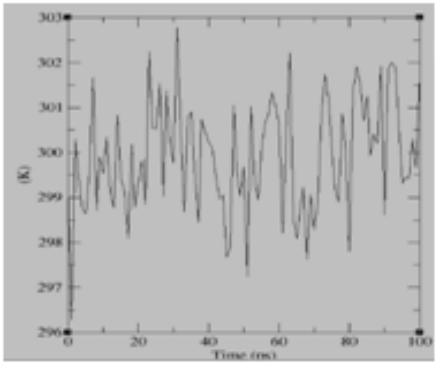

D

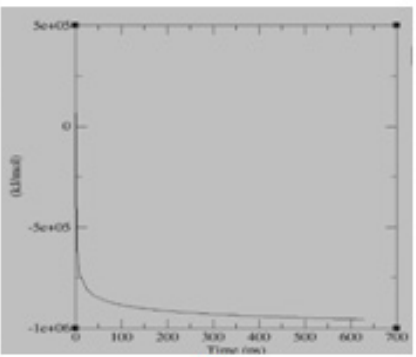

B

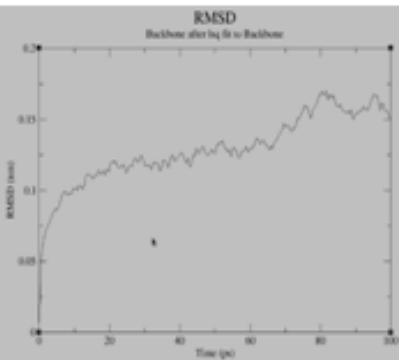

$\mathbf{E}$

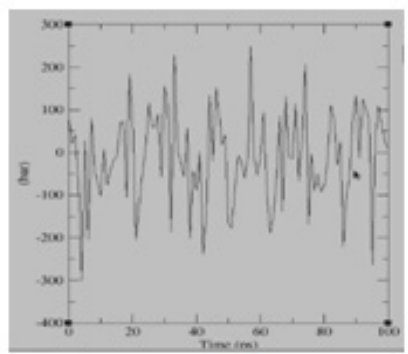

C

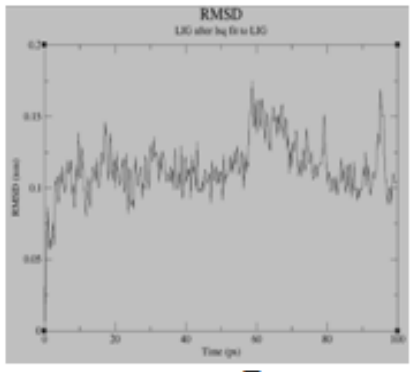

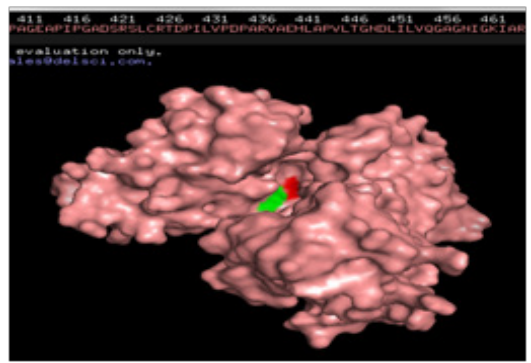

Figure 3.2 Molecular simulation results of complex MurE and rosmarinic acid. (A) Graph showing hydrogen bonds between the ligand-protein complex within the scale of $0.35 \mathrm{~nm}$; (B) GROMACS energy graph showing potential energy graph between ligand-protein complex; (C) GROMACS energy graph showing pressure graph between ligand-protein complex; (D) GROMACS energy graph showing temperature graph between ligand-protein complex; (E) RMSD graph of protein; (F) RMSD graph of ligand-Drug; (G) Protein (green colour)-ligand (red colour) complex 


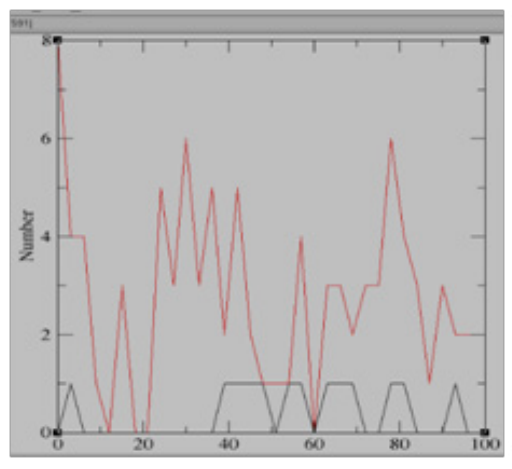

a

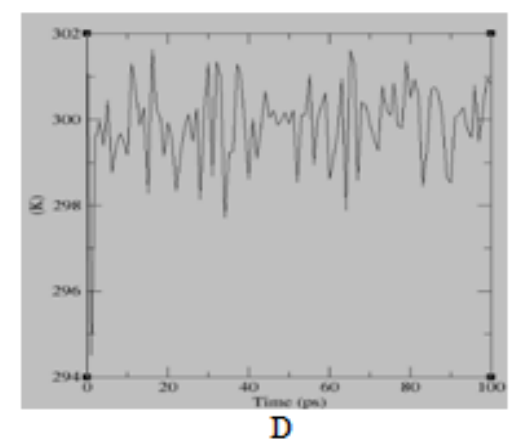

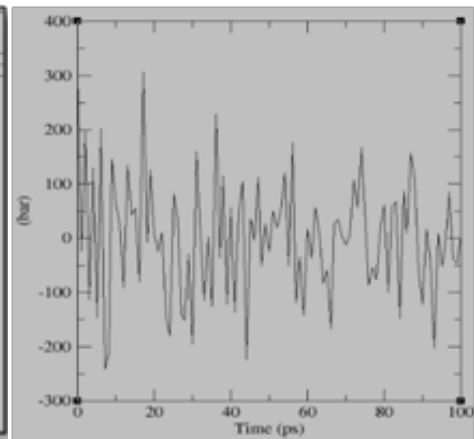

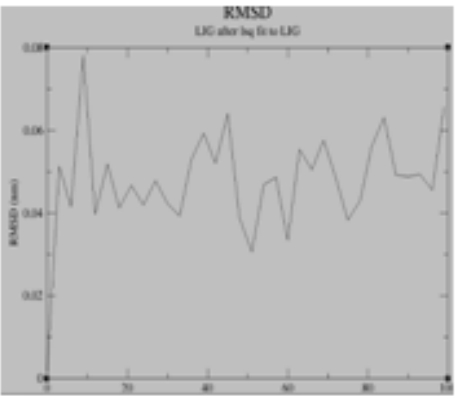

F

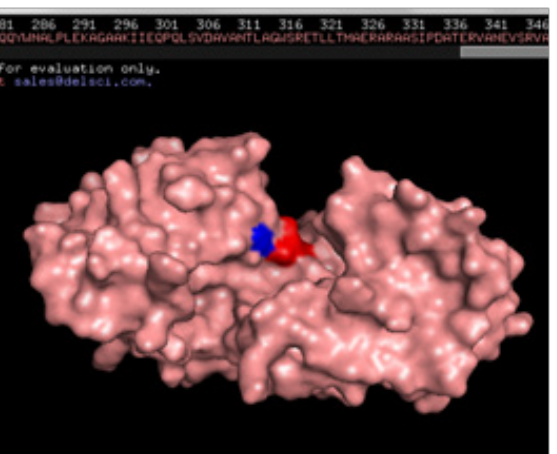

Figure 3.3 Molecular simulation results of complex MurG and Apigenin. (A) Graph showing hydrogen bonds between the ligand-protein complex within the scale of $0.35 \mathrm{~nm}$; (B) GROMACS energy graph showing potential energy graph between ligand-protein complex; (C) GROMACS energy graph showing pressure graph between ligand-protein complex; (D) GROMACS energy graph showing temperature graph between ligand-protein complex; (E) RMSD graph of protein; (F) RMSD graph of ligand-drug; (G) Protein (green colour)-ligand (red colour) complex

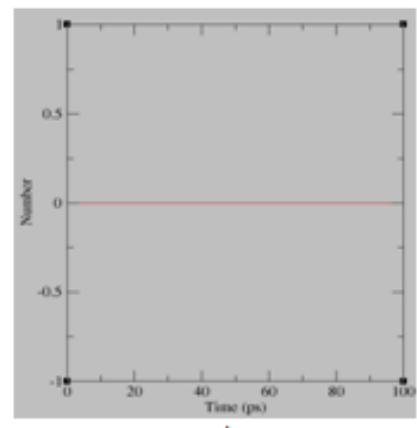

A

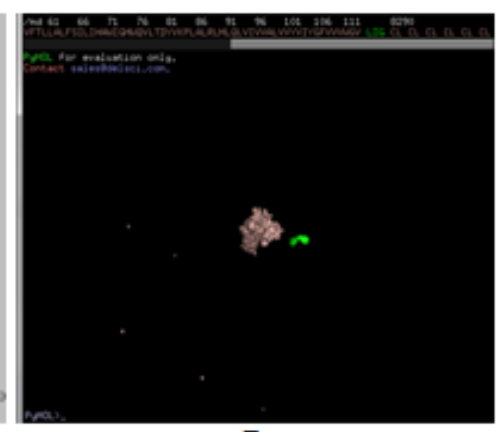

B

Figure 3.4 Molecular simulation results of complex SDH and rosmarinic acid. (A) Graph showing hydrogen bonds between the ligand-protein complex within the scale of $0.35 \mathrm{~nm}$; (B) After simulation for SDH it was concluded that there was no hydrogen bonds present between the protein and ligand.After visualization in PYMOL it was concluded that the drug moved out from its cavity 
Table 5 Free binding energy of the various ligands with respective target enzymes

\begin{tabular}{|c|c|c|}
\hline Name of The Target & $\begin{array}{l}\text { Name of The } \\
\text { Compound }\end{array}$ & $\begin{array}{l}\text { Binding } \\
\text { Energy }(\mathrm{Kcal} / \mathrm{Mol})\end{array}$ \\
\hline Succinate Dehydrogenase & Apigenin & -6.1 \\
\hline Succinate Dehydrogenase & Rosmarinic acid & -9.4 \\
\hline Succinate Dehydrogenase & Eugenol & -4.7 \\
\hline Succinate Dehydrogenase & Ocimarin & -7.5 \\
\hline Succinate Dehydrogenase & Carvacrol & -4.9 \\
\hline MurE & Apigenin & -9.3 \\
\hline MurE & Rosmarinic acid & -6.5 \\
\hline MurE & Eugenol & -6.2 \\
\hline MurE & Ocimarin & -5.2 \\
\hline MurE & Carvacrol & -6.3 \\
\hline MurG & Apigenin & -7.7 \\
\hline MurG & Rosmarinic acid & -7 \\
\hline MurG & Eugenol & -5.9 \\
\hline MurG & Ocimarin & -6.2 \\
\hline MurG & Carvacrol & -6.1 \\
\hline DNA Adenine Methylase & Apigenin & -8.1 \\
\hline DNA Adenine Methylase & Rosmarinic acid & -9 \\
\hline DNA Adenine Methylase & Eugenol & -5.7 \\
\hline DNA Adenine Methylase & Ocimarin & -6.7 \\
\hline DNA Adenine Methylase & Carvacrol & -5.9 \\
\hline DNA Primase & Apigenin & -6.6 \\
\hline DNA Primase & Rosmarinic acid & -7.6 \\
\hline DNA Primase & Eugenol & -5.3 \\
\hline DNA Primase & Ocimarin & -5.7 \\
\hline DNA Primase & Carvacrol & -5.2 \\
\hline
\end{tabular}

\section{Conclusion}

In order to overcome the menace of bacterial infections, the development of new antibiotics that interacts with essential elements of bacterial pathways will be required. Virtual screening approaches like docking and molecular simulation are very useful in identifying new inhibitors and also to design new altered/manipulated chemical moiety with great antibacterial potential. These screened potential phytochemicals may further be used to confirm their antimicrobial potency using wet lab experiments. So, in conclusion, this study may be helpful in guiding and designing new research area on identification of potential phytochemicals and their mode of inhibition against the pathogenic microbes.

\section{Acknowledgements}

Authors are grateful to Dr. Vinod Mittal (M.D), Dolphin (P.G) College of Science and Agriculture for providing financial supports to this study. We are highly indebted to the Principal, Dr. S.P. Jindal, for his encouragement to present research and giving final shape to this paper.

\section{Conflict of interest}

The authors declare there is no conflict of interest.

\section{References}

1. Chattopadhyay RR, Bhattacharyya SK, Medda C, et al. A Comparative Evaluation of Antibacterial Potential of Some Plants Used in Indian Traditional Medicine for the Treatment of Microbial Infections. Brazilian archives of Biology and Technology. 2009;52(5):1123-1128.

2. Kaur S, Mandal P. Study of total phenolic and flavonoid content, antioxidant activity and antimicrobial properties of medicinal plants. Journal of Microbiology and Experimentation. 2014;1(1):1-6.

3. Sinha S, Mishra P, Amin H, et al. A new cytotoxic quinolone alkaloid and a pentacyclic steroidal glycoside from the stem bark of Crataeva nurvala: Study of antiproliferative and apoptosis inducing property. European Journal of Medicinal Chemistry. 2013;(60):490-496.

4. Mistry KS, Sanghvi Z, Parmar G, et al. The antimicrobial activity of Azadirachata indica, Tinospora cardifolia, Ocimum sanctum and $2 \%$ chlorhexidine gluconate on common endodontic pathogens: An in vitro study. Eur J Dent. 2014;8(2):172-177.

5. Ahmad I, Mehmood Z, Mohammad F. Screening of some Indian medicinal plants for their antimicrobial properties. J Ethnopharmacol. 2008;62(2):183-193.

6. Ncube NS, Afolayan AJ, Okoh AI. Assessment techniques of antimicrobial properties of natural compounds of plant origin: current methods and future trends. Afr J Biotechnol. 2008;7(12):1797-1806.

7. Das K, Tiwari RKS, Shrivastava DK. Techniques for evaluation of medicinal plant products as antimicrobial agent: Current methods and future trends. J Med Plants Res. 2010;4(2):104-111.

8. Pahal V, Kaur A, Dadhich KS. Synergistic antibacterial effect of some Indian medicinal plants and cow Bos indicus urine distillate against selective pathogenic gram-positive bacteria. Int J Pharm Sci Res. 2016;7(11):1000-1009.

9. Prasad MP, Jayalakshmi K, Rindhe GG. Antibacterial activity of Ocimum species and their phytochemical and antioxidant potential. International journal of microbiology research. 2012;4(8):1-302.

10. Tantry BA, Kumar A, Rahiman S, et al. Antibacterial evaluation and phytochemical screening of methanolic extract of Ocimum sanctum against some common microbial pathogens. Global advanced research journal of microbiology. 2016;5(1):10-15.

11. Shaik G, Sujatha N, Mehar SK. Medicinal plants as source of antibacterial agents to counter Klebsiella pneumoniae. Journal of applied pharmaceutical science. 2014;4(1):135-147.

12. Lehrer RI, Rosenman M. Ultrasensitive assays for endogenous antimicrobial polypeptides. Journal of microbiological methods. 1991;137(2):167-173.

13. Al-Bakri GA, Afifi FU. Evaluation of antimicrobial activity of selected plant extracts by rapid XTT colorimetry and bacterial enumeration. Journal of Microbiological Methods. 2007;68(1):19-25.

14. Soni A, Sosa S. Phytochemical analysis and free radical scavenging potential of herbal and medicinal plant extracts. Journal of Pharmacognosy and Phytochemistry. 2013;2(4):22-29. 
15. Suresh MX, Pushpa OB. In silico studies on structure prediction and inhibitory action of selected natural compounds on cell invasion protein SipB from Salmonella typhi. Asian journal of biomedical and pharmaceutical sciences. 2014;4(3):20-24.

16. Kumar SP, Srinivasan P, Patel SK, et al. In silico development of inhibitors against pantothenate synthase of Mycobacterium tuberculosis. Journal of Advanced Bioinformatics Applications and Research. 2011;2(2):142-148.

17. Shilpi JA, Ali MT, Saha S, et al. Molecular docking studies on Inha Maba and Pank enzymes from Mycobacterium tuberculosis of ellagic acid derivatives from Ludwigia adscendens and Trewia nudiflora. In Silico Pharmacology. 2015;3(10):1-7.

18. Ferreira LG, Santos RN, Oliva G, et al. Molecular docking and structurebased drug design strategies. Molecules. 2015;20(7):13384-13421.

19. Shukla S, Gupta S. Apigenin: a promising molecule for cancer prevention. Pharm Res. 2010;27(6):962-978.

20. Jeong HJ. Rosmarinic acid, active component of Dansam-Eum attenuates ototoxicity of cochlear hair cells through blockage of caspase-1 activity. PLoS One. 2011;(6):18815.

21. Nostro A, Roccaro AS, Bisignano G, et al. Effects of Oregano, Carvacrol and Thymol on Staphylococcus aureus and Staphylococcus epidermidis biofilms. Journal of Medical Microbiology. 2007;(56):519-523.

22. Knowles JR, Roller S, Murray DB et al. Antimicrobial action of carvacrol at different stages of dual-species biofilm development by Staphylococcus aureus and Salmonella enterica serovar Typhimurium. Appl Environ Microbiol. 2005;(71):797-803.

23. Gupta P, Yadav DK, Siripurapu KB, et al. Constituents of Ocimum sanctum with Antistress Activity. J Nat Prod. 2007;70(9): 1410-1416.

24. Meng XY, Zhang HX, Mezei M, et al. Molecular docking: A powerful approach for structure-based drug discovery. Curr Comput Aided Drug Des. 2011;7(2):146-157.

25. Bozdaganyan ME, Orekhov PS, Bragazzi NL, et al. Docking and Molecular simulations in potential drugs discovery: An application to Influenza virus M2 protein. American journal of biochemistry and biotechnology. 2014;10(3):180-188.

26. Pronk S, Pall S, Schulz R, et al. Gromacs 4.5: A high-throughput and highly parallel open source molecular simulation toolkit. Bioinformatics. 2013;29(7):845-854.

27. Xin Yi, Zhang $\mathrm{Y}$, Wang $\mathrm{P}$, et al. Ligands binding and molecular simulation: the potential investigation of a biosensor based on an insect odorant binding protein. Int J Biol Sci. 2015;11(1):75-87.
28. Schlick T, Collepardo-Guevara R, Halvorsen LA, et al. Biomolecular modelling and simulation: a field coming of age. Quarterly Reviews of biophysics. 2011;44(2):191-228.

29. Park SJ, Tseng CP, Gunsalus RP. Regulation of succinate dehydrogenase (sdhCDAB) operon expression in Escherichia coli in response to carbon supply and anaerobiosis: role of Arca and Fnr. Mol Microbiol. 1995;15(3):473-482.

30. Ahmed EZ, Francois S, and Roger CL. Structure and function of the Mur enzymes: development of novel inhibitors. Molecular Microbiology. 2003;47(1):1-12.

31. Gardete S, Ludovice AM, Sobral RG, et al. Role of mure in the Expression of Lactam Antibiotic Resistance in Staphylococcus aureus. Journal of Bacteriology. 2004;186(6):1705-1713.

32. Tamimount M, Karczmarek A, Crouvoisier M, et al. The essential peptidoglycan glycosyltrans ferase Murg forms a complex with proteins involved in lateral envelope growth as well as with proteins involved in cell division in Escherichia coli. Molecular Microbiology. 2007;65(4):1106-1121.

33. Low DA, Weyand NJ, Mahan MJ. Roles of DNA Adenine Methylation in Regulating Bacterial Gene Expression and Virulence. Infection and Immunity. 2001;69(12):7197-7204.

34. Guilliam TA, Keen BA, Brissett NC, et al. Primase-polymerases are a functionally diverse superfamily of replication and repair enzymes. Nucleic Acids Research. 2015;43(14):6651-6664.

35. Joshi B, Sah GP, Basnet BB, et al. Phytochemical extraction and antimicrobial properties of different medicinal plants: Ocimum Sanctum (Tulsi), Eugenia Caryophyllata (clove), Achyranthes bidentate (datiwan) and Azadirachta indica (Neem). Journal of Microbiology and Antimicrobials. 2011;3(1):1-7.

36. Sabbagh G, Berakdar N. Molecular docking study of flavonoid compounds as inhibitors of B-ketoacyl acyl carrier protein synthase II (KAS II) of Pseudomonas aeruginosa. International journal of pharmacy and pharmaceutical sciences. 2016;8(1):52-61.

37. Georrge JJ, Umrania V. In silico identification of putative drug targets in Klebsiella pneumonia MGH78578. Indian journal of biotechnology. 2011;10(4):432-439.

38. Panchal HK, Trivedi RA, Desai PB. Docking studies of components of Tulsi and Mamejavo against Plasmodium Lactate dehydrogenase. International research journal of biological sciences. 2013;2(2):8-12. 